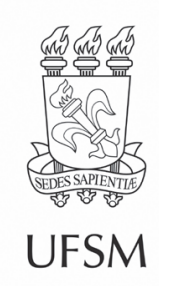

\title{
Artigos
}

\section{Crescimento de Syagrus romanzoffiana (Cham.) Glassman após resgate e realocação em unidade de conservação urbana}

\author{
Growth of Syagrus romanzoffiana (Cham.) Glassman after rescue and \\ relocation in an urban conservation unit
Marina Crestana Guardia ${ }^{\oplus}$, Shoey Kanashiro ${ }^{\circ}{ }^{\circ}$, Vívian Tamaki ${ }^{\bullet}$, Catarina Carvalho Nievola ${ }^{\circ}$, Rogério Mamoru Suzuki ${ }^{\oplus}$, Janaina Pinheiro Costa $1 \odot$, Waldyr Baptista "๑, Yoshito Shidomi I ${ }^{\oplus}$, Mônicá Valéria Cachenco '`, Nelson Augusto dos Santos Junior $1 \odot$

' Instituto de Botânica, São Paulo, SP, Brasil

" Instituto de Botânica, in memoriam

\section{RESUMO}

A Mata Atlântica é um bioma constantemente ameaçado por perturbações antrópicas. A supressão da vegetação por obras rodoviárias ressalta a necessidade de projetos de conservação das espécies que nela ocorrem. O sucesso do resgate e realocação de plantas, como a palmeira Syagrus romanzoffiana pode contribuir para a conservação dessas espécies. O objetivo deste trabalho foi estudar o crescimento de mudas de S. romanzoffiana resgatadas de áreas de supressão da obra do Rodoanel Mário Covas Trecho Norte e transplantadas em áreas naturais do Parque Estadual da Cantareira, São Paulo -SP. Foram obtidas medidas de altura, diâmetro do coleto, número de folhas e volume do torrão das mudas. O transplante foi realizado em três condições de luminosidade depois de separadas em três classes de volume de torrão e três classes de diâmetro do coleto. Foram avaliadas a porcentagem de sobrevivência, incremento em altura, diâmetro do coleto, número de folhas e pigmentos fotossintéticos após 4,8 e 12 meses. O delineamento experimental foi inteiramente casualizado em esquema fatorial $3 \times 3 \times 3$ (luminosidade $x$ diâmetros do coleto $x$ volumes do torrão) com três repetições de cinco plantas cada. Os dados obtidos foram submetidos à análise de variância e as médias comparadas entre si através do teste de Tukey (5\%). A sobrevivência foi superior a $80 \%$ em todos os ambientes. Houve maior crescimento, principalmente quanto ao diâmetro do coleto, na clareira pequena. A quantificação de clorofila $a, b$ e carotenoides mostrou maior teor para as plantas mantidas no sombreamento. Quanto à razão clorofila $a / b$, os resultados evidenciaram maiores valores nas plantas mantidas no sombreamento, com valores crescentes até os 12 meses. Pode-se concluir que S. romanzoffiana apresenta pouca restrição quanto ao ambiente de realocação, porém, com preferência às clareiras pequenas, sendo dispensável que sejam realocadas com torrão de porte grande.

Palavras-chave: Arecaceae; Resgate de plantas; Realocação de plantas; Medidas compensatórias 


\begin{abstract}
The Atlantic Forest is a biome constantly threatened by human disturbances. The suppression of vegetation by road works highlights the need for conservation projects for the species that occur there. The success of rescuing and relocating plants, such as the Syagrus romanzoffiana palm, can contribute to the conservation of these species. The objective of this work was to study the growth of S. romanzoffiana seedlings rescued from areas of suppression of the "Rodoanel Mário Covas" - North Section - and transplanted in natural areas of the Cantareira State Park, São Paulo, SP state. Measurements of height, stem diameter, number of leaves and clod volume of seedlings were obtained. The transplant was carried out in three light conditions after being separated into three clod volume classes and three crown diameter classes and observed for one year. The percentage of survival increase in height, crown diameter, number of leaves and photosynthetic pigments were evaluated. The experimental design was completely randomized in a $3 \times 3 \times 3$ factorial scheme (luminosity $\times$ crown diameters $\times$ clod volumes) with three replications of five plants each. The data obtained were subjected to analysis of variance and the means compared to each other using the Tukey test (5\%). Survival was over $80 \%$ in all environments. There was greater growth, mainly regarding the stem diameter, in the small clearing. The quantification of chlorophyll $a, b$ and carotenoids, showed higher pigments content for plants kept in the shade. As for the chlorophyll $a / b$ ratio, the results showed a greater relationship in plants kept in shade, with increasing values up to 12 months. It can then be concluded that S. romanzoffiana has little restriction on the relocation environment, but with preference for small clearings, and it is unnecessary that they are relocated with large clod.
\end{abstract}

Keywords: Arecaceae; Plant rescue; Plant relocation; Compensatory measures

\title{
1 INTRODUÇÃo
}

As paisagens antrópicas já dominam diversas regiões tropicais e a expansão das mesmas impõe ameaças sérias à diversidade biológica, uma vez que pequenos fragmentos e bordas florestais podem apresentar capacidade limitada de reter espécies e de prover serviços ambientais essenciais às populações humanas, como o sequestro de carbono, o controle de enchentes e a proteção do solo (TABARELLI et al., 2012).

Os impactos humanos têm efeito na distribuição das espécies. A Mata Atlântica, internacionalmente conhecida pelo alto número de espécies e de endemismos, é um dos biomas tropicais mais ameaçados do mundo, sobretudo pela perda e fragmentação dos habitats naturais (LEMES; LOYOLA, 2015).

No cenário crítico da conservação da Mata Atlântica, todo remanescente é 
importante para a conservação das espécies (RIBEIRO et al., 2009). Esse é um dos biomas brasileiros considerados como hotspots prioritários para a conservação. É um complexo conjunto de ecossistemas florestais que abriga uma parcela significativa da diversidade biológica do Brasil e um dos biomas mais ameaçados, devido às constantes perturbações ou ameaças de destruição dos habitats e ecossistemas associados (FERREIRA, 2007). Dessa forma, projetos de conservação e preservação da Mata Atlântica e das espécies que nela ocorrem têm se tornado cada vez mais necessários.

Apesar do número crescente de trabalhos, relatos de pesquisas que proporcionem o conhecimento das espécies nativas brasileiras, principalmente em seus estádios iniciais de desenvolvimento, e que possam servir de referência para os programas de recuperação e manejo de áreas naturais são escassos (LEONHARDT et al., 2008). Ações de conservação, descritas por Oliveira (2014), enfatizam a importância do resgate de plantas de áreas naturais a serem suprimidas. Santos Júnior e Tamaki (2014) destacam a importância da realocação para remanescentes de vegetação próximos, prioritariamente em Unidades de Conservação.

Nave (2005) e Silva et al. (2015) definiram parâmetros para o resgate de plantas de seu ambiente de origem, e Inácio e Leite (2007), verificaram a viabilidade de se transplantar em outro local. O transplante, ou realocação, tem sido uma alternativa para salvar as árvores para projetos de uso e ocupação do solo nas grandes cidades (INÁCIO; LEITE, 2007). Segundo Calegari et al. (2011), essa técnica apresenta vantagens como eliminar etapas tradicionais de produção por sementes, ocasionando redução no custo de produção, melhor adaptação ao clima, favorecendo a conservação do material genético. O resgate de algumas espécies e posterior realocação para áreas protegidas é um procedimento de mitigação importante que pode ser adotado durante a supressão da vegetação (JASPER et al., 2005).

Dentre as espécies passíveis de transplante, Sanchotene (2000) descreve como as mais usuais, as palmeiras, que são muito utilizadas no paisagismo e apresentam 
em torno de $90 \%$ de sucesso na taxa de sobrevivência após o transplante. Lorenzi (1996) comenta que o jerivá (Syagrus romanzoffiana) é a palmeira mais empregada na arborização de ruas e avenidas em todo o país, por ter facilidade de adaptação ao transplante quando adulta. S. romanzoffiana pertence à família Arecaceae, é heliófita, seletiva higrófila e pioneira com ampla dispersão na América do Sul, sendo nativa do Brasil, Uruguai e Argentina. A família Arecaceae é um importante componente da flora da Mata Atlântica (ALVES et al., 2011). Além da reconhecida importância ecológica e econômica, S. romanzoffiana tem sido considerada uma espécie de grande relevância em ações de resgate e realocação (BERNACCI; MARTINS; SANTOS, 2008).

Em São Paulo, para minimizar o congestionamento viário na região central da cidade, o Governo do Estado iniciou em 1998 a construção de uma rodovia periférica, que recebeu o nome de "Rodoanel Mario Covas". O Trecho Norte do Rodoanel, com 47,5 km de extensão, atravessa extensa área de Mata Atlântica, dentro do Parque Estadual da Cantareira (PEC). O PEC possui 7.916,52 ha e é considerado uma das maiores florestas urbanas do planeta, sendo um dos principais remanescentes florestais da região metropolitana de São Paulo. Na região há muitas nascentes, e a Unidade de Conservação é considerada pela Unesco como a Zona Central da Reserva da Biosfera do Cinturão Verde da Cidade de São Paulo (SÃO PAULO, 2010).

A supressão da vegetação para construção do Rodoanel pode ser considerada um impacto sobre a mata nativa. Assim, o resgate de espécies e sua realocação podem ser fundamentais para a preservação ambiental e a manutenção da diversidade genética. Contudo, é necessária a avaliação da viabilidade desses processos.

Nesse contexto, o estudo do crescimento e desenvolvimento de plantas transplantadas em ambientes com diferentes intensidades luminosas pode ser de grande importância, pois diferentes condições de luminosidade podem alterar os teores de pigmentos fotossintéticos e a consequente taxa fotossintética, devendo ser considerados em programas de introdução e adaptação de espécies (BRAHM, 2010).

O crescimento vegetal é limitado pelos pigmentos fotossintéticos (clorofila $a$, 
b e carotenoides), que são estruturas químicas instáveis e facilmente degradáveis, podendo alterar a qualidade e percepção luminosa dos vegetais (THIESEN et al., 2017). As alterações luminosas no ambiente de cultivo proporcionam ajustes do aparelho fotossintético das plantas, os quais resultam em uma maior eficiência na absorção e transferência de energia para os processos fotossintéticos. Nesse contexto, os teores dos pigmentos podem ser utilizados como importantes marcadores de ambientação do vegetal (MARTINS et al., 2010).

Diante do exposto, o objetivo desta pesquisa foi estudar o crescimento de mudas de Syagrus romanzoffiana resgatadas de áreas de supressão da obra do Rodoanel Mário Covas - Trecho Norte, e realocadas em áreas naturais em diferentes condições de luminosidade, no Parque Estadual da Cantareira, São Paulo- SP.

\section{MATERIAL E MÉTODO}

\subsection{Material e local de estudo}

Foram obtidas 150 mudas de Syagrus romanzoffiana (Cham.) Glassman provenientes do resgate em áreas suprimidas para a obra de construção do Rodoanel Mário Covas - Trecho Norte, em fragmentos de Mata Atlântica nos municípios de Arujá e São Paulo, São Paulo, Brasil. Após o resgate, as mudas foram colocadas em vasos plásticos de três classes de tamanhos, utilizando-se terra do local do resgate como substrato. Os vasos foram depositados em ambiente de viveiro coberto com tela de sombreamento e irrigados duas vezes por semana até o transplante. As mudas foram caracterizadas pelas medidas de altura (realizada com trena do solo à gema apical), diâmetro do coleto (realizada com paquímetro), número de folhas (somadas folhas simples e pinadas) e volume do torrão (realizada com trena e transformada para litro) e separadas em três classes quanto ao diâmetro do coleto e em três classes quanto ao volume do torrão. As médias de diâmetro do coleto para cada classe foram de: 11,4, 19,2 e 30,0 mm. As médias de volume do torrão para cada classe foram de 1,6, 2,6 e 4,1 litros, respectivamente. 
O transplante ocorreu em 24 de novembro de 2015 em áreas de mata do Núcleo do Engordador do Parque Estadual da Cantareira (PEC), do Instituto Florestal de São Paulo, no município de São Paulo, Estado de São Paulo, Brasil. A realocação foi realizada em três áreas de Floresta Ombrófila Densa, diferentes quanto à luminosidade, denominadas clareira grande $\left(23^{\circ} 24^{\prime} 37^{\prime \prime} S, 46^{\circ} 35^{\prime} 23^{\prime \prime} \mathrm{W}\right)$, clareira pequena $\left(23^{\circ} 24^{\prime} 13^{\prime \prime} \mathrm{S}\right.$, $\left.46^{\circ} 35^{\prime} 12^{\prime \prime} \mathrm{W}\right)$ e sombreamento $\left(23^{\circ} 24^{\prime} 36^{\prime \prime} \mathrm{S}, 4^{\circ} 35^{\prime} 24^{\prime \prime} \mathrm{W}\right)$. A caracterização desses ambientes foi realizada no início do experimento e repetida em todas as datas nas quais foram realizadas as avaliações, utilizando-se um luxímetro digital Minipa, em três pontos de coleta aleatórios para cada condição de luminosidade. Os valores em lux foram convertidos para $\mu \mathrm{mol} \cdot \mathrm{m}^{-2} \cdot \mathrm{s}^{-1}$. A intensidade luminosa média dos três ambientes foi de $833,83,418,55$ e 133,20 $\mu \mathrm{mol} . \mathrm{m}^{-2} \cdot \mathrm{s}^{-1}$, respectivamente. Para efeito metodológico, a área denominada clareira grande foi considerada com $100 \%$ de incidência luminosa, e, proporcionalmente, os ambientes clareira pequena e sombreamento apresentaram as luminosidades de $50,2 \%$ e $16,0 \%$, respectivamente.

A classificação climática da área de realocação, segundo Köppen (1948), é Cfb, caracterizada pelo clima úmido com pequenas deficiências de chuvas, mesotérmica e com excesso de chuvas no verão. Segundo o Plano de Manejo do PEC (SÃO PAULO, 2010), essa área apresenta precipitação média de $1.322 \mathrm{~mm}$ por ano, sendo janeiro o mês mais chuvoso, com 229,8 mm e agosto o menos chuvoso, com 31,7 mm. As temperaturas variam de $16,5^{\circ} \mathrm{C}$ (junho e julho) a $26,0^{\circ} \mathrm{C}$ (janeiro e fevereiro), superando $34,0^{\circ} \mathrm{C}$ nos meses mais quentes e com umidade relativa do ar de $83,7 \%$. O registro dos fatores ambientais relativos ao período do estudo é apresentado na Figura 1.

O período de observação foi de novembro de 2015 a novembro de 2016. As covas foram feitas nas dimensões de $40 \times 40 \times 40 \mathrm{~cm}$, tendo a distribuição das mudas a forma linear com espaçamento de 2,0 x 2,0 m, nas três áreas escolhidas. Após o transplante foram realizados tratos culturais em campo, consistindo em roçadas periódicas. 
As variáveis observadas em todas as plantas foram porcentagem de sobrevivência das mudas, incremento em altura, diâmetro do coleto e número de folhas total (soma de folhas simples e pinadas). Valores médios foram obtidos aos 4, 8 e 12 meses após o transplante das plantas. A luminosidade incidente nas plantas foi medida com luxímetro digital. As leituras spad para a correlação com as quantidades de pigmentos fotossintéticos extraídas em laboratório foram realizadas em três folhas de três plantas escolhidas aleatoriamente utilizando-se um clorofilômetro Konika Minolta Spad-502 plus. Em laboratório foi elaborada uma curva padrão com valores obtidos pelo clorofilômetro e com as análises de quantidades de clorofilas e carotenoides, realizados pelo método colorimétrico e avaliados em espectrofotômetro (LICHTENTHALER, 1981). Os valores de clorofila $a$, clorofila $b$ e carotenoides foram expressos em $\mu$ g pigmento.g massa fresca-1. Foi calculada também a razão entre as clorofilas $a / b$.

Figura 1 - Valores mensais de precipitação $(\mathrm{mm})$ e temperaturas mínima, média e máxima $\left({ }^{\circ} \mathrm{C}\right)$ na Zona Norte de São Paulo - SP, para o período de novembro de 2015 a novembro de 2016. Os dados foram disponibilizados pelo Instituto Meteorológico Nacional (INMET), utilizando o Banco de Dados Meteorológicos para Ensino e Pesquisa (BDMEP)

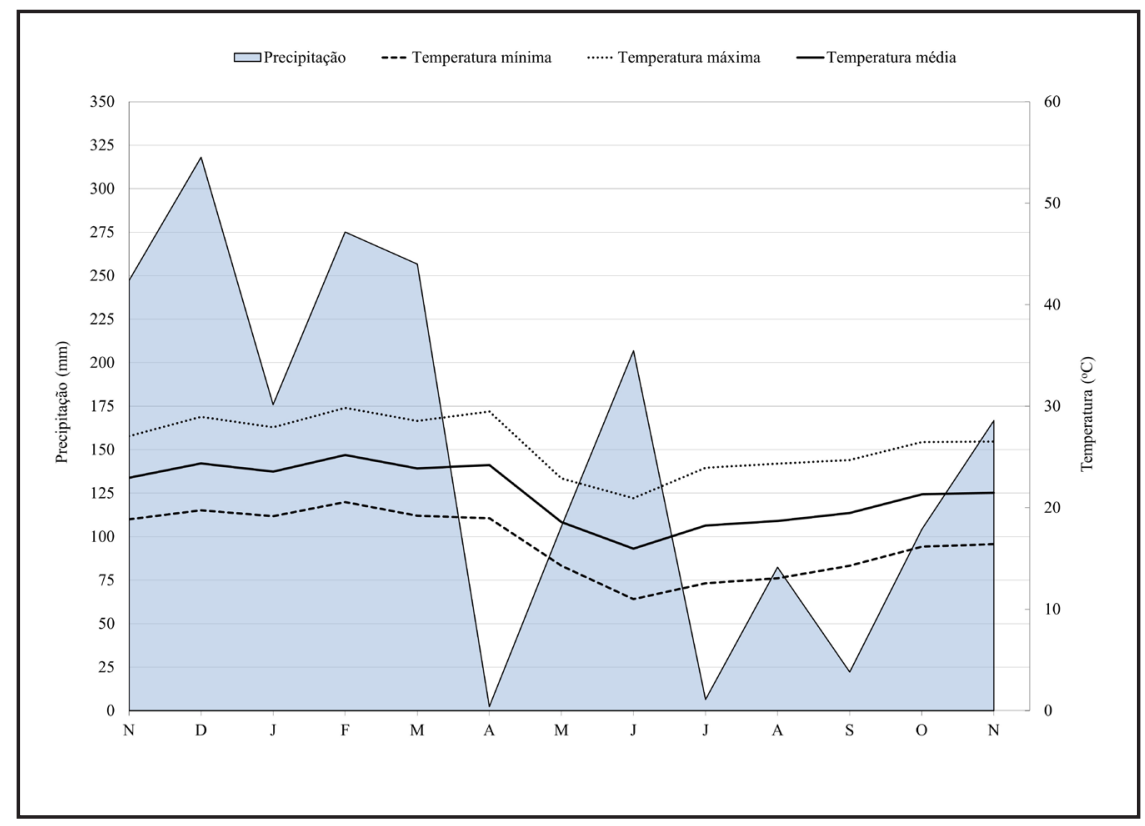

Fonte: Autores (2020) 


\subsection{Delineamento experimental}

O delineamento experimental adotado foi o inteiramente casualizado, na forma fatorial $3 \times 3 \times 3$, consistindo em três classes de diâmetros do coleto, três diferentes luminosidades e três classes de volumes de torrão, com três repetições e cinco plantas por parcela. Os dados obtidos foram submetidos à análise de variância (teste F) e as médias foram comparadas entre si através do teste de Tukey em nível de $5 \%(p \leq 0,05)$ utilizando o software Sisvar (FERREIRA, 2011). Médias, desvios padrões e coeficientes de variação foram calculados de acordo com os procedimentos descritos por Sokal e Rohlf (1980).

\section{RESULTADOS E DISCUSSÃO}

A taxa de sobrevivência das mudas de S. romanzoffiana variou de 80 a 100\% entre os tratamentos (Figura 2). Esse resultado foi superior aos obtidos por Knapik e Maranho (2007), que registraram 76\% de sobrevivência em um plantio de restauração realizado no Paraná, após um ano, e próximo àqueles obtidos por Inácio e Leite (2007), em um plantio urbano da espécie no Rio Grande do Sul, com 100\% de sobrevivência, também após um ano de avaliação, indicando que o resultado deste trabalho está dentro da média observada para a realocação da espécie.

Ainda na Figura 2, nota-se que, ao longo das três avaliações e até o período de 12 meses, não houve efeito do tamanho do torrão na sobrevivência das plantas de $S$. romanzoffiana, considerando-se os três ambientes. No que diz respeito à comparação dos ambientes, até os quatro meses, não houve efeito desse fator, contudo, a partir da segunda avaliação, aos oito meses, os valores de sobrevivência foram maiores na clareira grande e no sombreamento, quando comparados à clareira pequena, dentro de uma mesma classe de tamanho de torrão. Os resultados apontam para uma grande plasticidade da espécie no que diz respeito ao ambiente. Brancalion, Novembre e Rodrigues (2011), em estudos de germinação de sementes da espécie 
em duas formações vegetais bem distintas (floresta atlântica e restinga) com enfoque para a restauração, também destacam essa plasticidade.

Figura 2 - Porcentagem de sobrevivência de plantas de Syagrus romanzoffiana, realocadas em três condições de luminosidade (clareira grande, clareira pequena e sombreamento) e com três tamanhos de torrão (maior, intermediário e menor), avaliadas aos 4, 8 e 12 meses, em São Paulo - SP, Brasil. Médias seguidas pela mesma letra não diferem entre si, em nível de 5\% pelo teste Tukey. Letras maiúsculas comparam os tamanhos de torrão dentro de uma dada condição e letras minúsculas comparam as condições dentro de um dado tamanho de torrão, sempre na mesma data

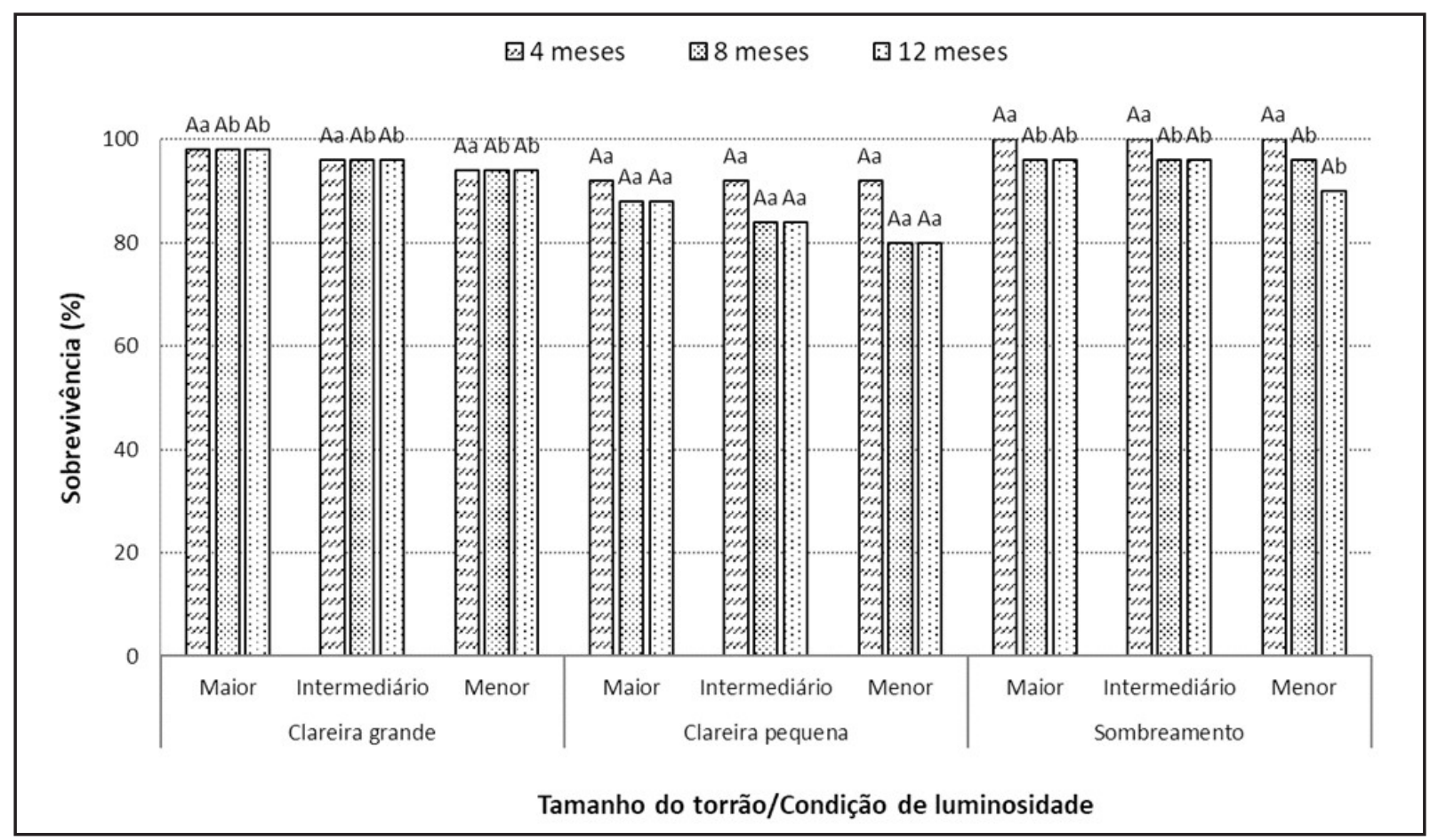

Fonte: Autores (2020)

A Figura 3 apresenta os valores médios de incremento em altura (A), em diâmetro do coleto (B) e número total de folhas (C). Destacam-se as diferenças observadas nas plantas de S. romanzoffiana com torrão maior, que apresentaram maiores valores de incremento em altura a partir do oitavo mês na clareira grande e no sombreamento, e no $12^{\circ}$ mês, nos três ambientes (Figura 3A, Tabela 1). No que diz respeito à comparação 
dos ambientes, a clareira pequena, com cerca de $50 \%$ de luminosidade, foi o ambiente no qual as plantas apresentaram os maiores valores de incremento em altura. Moraes Neto et al. (2000) e Carvalho et al. (2006) enfatizam que o ganho em altura em ambientes sombreados é um mecanismo de adaptação, compreendendo uma estratégia para sair desse sombreamento.

No ambiente de clareira pequena também foram encontrados os maiores valores de incremento de diâmetro do coleto, quando comparado com os dois outros ambientes, logo a partir da segunda avaliação (Figura 3B), e de forma bem acentuada aos 12 meses (Tabela 1). Quando se compara o incremento no diâmetro do coleto entre as três classes de tamanho de torrão, aquele de maior tamanho propiciou também os maiores incrementos no $12^{\circ}$ mês na clareira grande, e logo na primeira avaliação (quarto mês) na clareira pequena e no sombreamento.

Com relação ao número de folhas (Figura 3C), é possível notar que, na clareira grande, todos os tratamentos se igualaram. Comparado aos demais ambientes, os maiores valores em número de folhas (média de 1,2 folhas/planta) foram novamente obtidos aos 12 meses, no menor tamanho de torrão, em clareira pequena.

Nodari et al. (1999) relatam que o número de folhas não é a característica mais indicada para representar diferenças no crescimento de plantas quando submetidas a diferentes condições de luminosidade, uma vez que ocorre queda e emissão de novas folhas continuamente. Mesmo assim, o número de folhas, desde que avaliado em conjunto com demais variáveis, pode ser um importante parâmetro, conforme afirmaram Carvalho et al. (2006), em estudo com plantas de licuri (Syagrus coronata).

Na Figura 4 são apresentadas a quantidade de clorofila $a, b$ e carotenoides (A) e a relação clorofila $a / b$ (B) de plantas de Syagrus romanzoffiana, realocadas em três condições de luminosidade (clareira grande, clareira pequena e sombreamento) e avaliadas aos 4, 8 e 12 meses.

As plantas podem passar por condições de estresse e modificar a quantidade de pigmentos fotossintéticos em resposta às diferentes condições de luminosidade. O aumento da razão clorofila $a / b$ pode estar correlacionado à proteção do sistema fotossintético, devido à menor absorção de radiação solar (CAMEJO; TORRES, 2001). 
Figura 3 - Valores médios de incremento em altura (A), em diâmetro do coleto (B) e número total de folhas (C) de plantas de Syagrus romanzoffiana aos 4, 8 e 12 meses, realocadas em três condições de luminosidade (clareira grande, clareira pequena e sombreamento) e com três diferentes tamanhos do torrão (maior, intermediário e menor), em São Paulo - SP, Brasil. Médias seguidas pela mesma letra não diferem entre si, em nível de 5\% pelo teste Tukey. Letras maiúsculas comparam os tamanhos de torrão dentro de uma dada condição e letras minúsculas comparam as condições dentro de um dado tamanho de torrão, sempre na mesma data

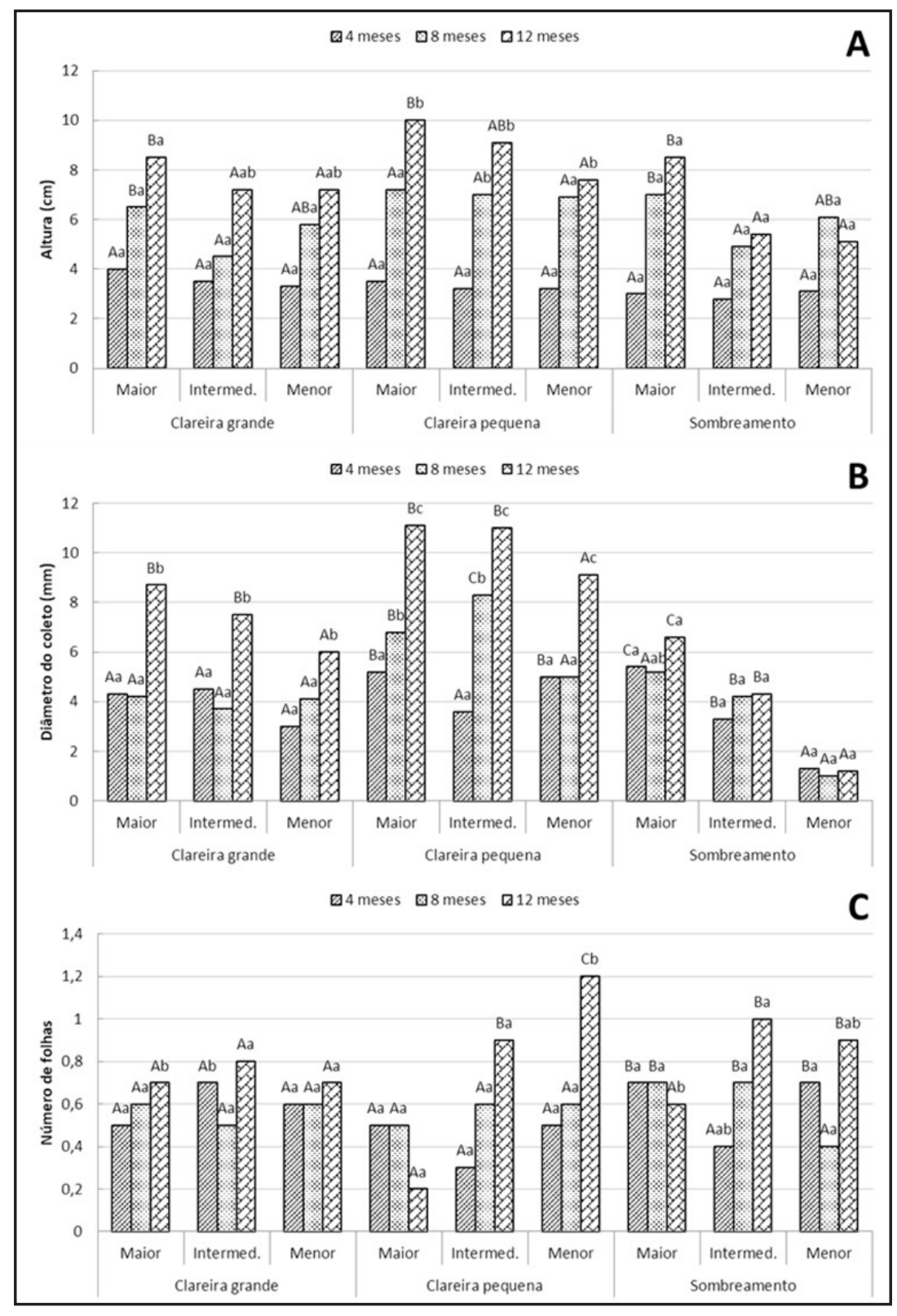

Fonte: Autores (2020) 
Neste estudo, as quantidades de clorofilas $a$ e $b$ e carotenoides (Figura 4A), bem como a razão clorofila $a / b$ (Figura 4B) foram maiores na condição de sombreamento quando comparadas aos demais ambientes na primeira avaliação (4 meses). Na avaliação seguinte (8 meses), a quantidade de ambos os pigmentos e a razão clorofila $a / b$ na clareira pequena elevaram-se, aproximando-se aos valores do sombreamento. Na terceira avaliação (12 meses), as plantas dos três ambientes passaram a apresentar as mesmas quantidades dos parâmetros avaliados podendo indicar uma adaptação gradual ao local de realocação.

Tabela 1 - Valores médios dos incrementos em altura (cm), diâmetro do coleto (mm) e número de folhas de plantas de Syagrus romanzoffiana, de acordo com o volume do torrão (maior, intermediário e menor), realocadas em três condições de luminosidade (clareira grande, clareira pequena e sombreamento), após 12 meses de avaliação, em São Paulo - SP, Brasil

\begin{tabular}{|c|c|c|c|c|c|}
\hline $\begin{array}{c}\text { Condição de } \\
\text { Luminosidade }\end{array}$ & & $\begin{array}{l}\text { Clareira } \\
\text { Grande }\end{array}$ & $\begin{array}{l}\text { Clareira } \\
\text { Pequena }\end{array}$ & Sombreamento & Média \\
\hline \multicolumn{6}{|c|}{ Incremento em altura $(\mathrm{cm})$} \\
\hline \multirow{3}{*}{$\begin{array}{l}\text { Volume do } \\
\text { torrão }\end{array}$} & Maior & $8,5 \mathrm{Aa}$ & $10,0 \mathrm{Aa}$ & $8,5 \mathrm{Aa}$ & $8,9 \mathrm{~A}$ \\
\hline & Intermediário & $7,2 \mathrm{Aa}$ & $9,1 \mathrm{Aa}$ & $5,4 \mathrm{Aa}$ & $7,2 \mathrm{~A}$ \\
\hline & Menor & $7,2 \mathrm{Aa}$ & $9,1 \mathrm{Aa}$ & $5,4 \mathrm{Aa}$ & $7,2 \mathrm{~A}$ \\
\hline Média & & $7,5 \mathrm{a}$ & $8,8 \mathrm{a}$ & $6,8 \mathrm{a}$ & 7,6 \\
\hline \multicolumn{6}{|l|}{$C V(\%)=39,16$} \\
\hline \multicolumn{6}{|c|}{ Incremento em diâmetro do coleto (mm) } \\
\hline \multirow{3}{*}{$\begin{array}{l}\text { Volume do } \\
\text { torrão }\end{array}$} & Maior & $8,7 \mathrm{Aa}$ & $11,1 \mathrm{Aa}$ & $6,6 \mathrm{Ba}$ & $8,4 \mathrm{~A}$ \\
\hline & Intermediário & 7,5 Aab & $11,0 \mathrm{Ab}$ & 4,3 ABa & $7,7 \mathrm{~A}$ \\
\hline & Menor & $6,0 \mathrm{Aab}$ & $9,1 \mathrm{Ab}$ & $1,2 \mathrm{Aa}$ & $6,0 \mathrm{~A}$ \\
\hline Média & & $7,0 \mathrm{a}$ & $10,4 b$ & 4,7 a & 7,3 \\
\hline \multicolumn{6}{|l|}{$\mathrm{CV}(\%)=49,84$} \\
\hline \multicolumn{6}{|c|}{ Incremento em número de folhas } \\
\hline \multirow{3}{*}{$\begin{array}{l}\text { Volume do } \\
\text { torrão }\end{array}$} & Maior & $0,7 \mathrm{Ab}$ & $0,2 \mathrm{Aa}$ & $0,6 \mathrm{Ab}$ & $0,5 \mathrm{~A}$ \\
\hline & Intermediário & $0,8 \mathrm{Aa}$ & $0,9 \mathrm{Ba}$ & $1,0 \mathrm{Aa}$ & $0,9 \mathrm{~A}$ \\
\hline & Menor & $0,7 \mathrm{Aa}$ & 1,2 Ba & $0,9 \mathrm{Aa}$ & $0,9 \mathrm{~A}$ \\
\hline Média & & $0,7 \mathrm{a}$ & $0,8 \mathrm{a}$ & $0,8 \mathrm{a}$ & 0,7 \\
\hline$C V(\%)=91,94$ & & & & & \\
\hline
\end{tabular}

Fonte: Autores (2020)

Em que: Médias seguidas pela mesma letra não diferem entre si em nível de 5\% de probabilidade pelo teste de Tukey. Letras maiúsculas comparam na vertical e minúsculas, na horizontal. 
A abundância de clorofilas e a proporção de clorofila $a$ e $b$ variam de acordo com a intensidade de luz à qual a planta está exposta. Givinish (1988) afirma que a proporção entre clorofilas $a$ e $b$, de maneira geral, tende a diminuir com a redução da luz, devido à maior proporção relativa de clorofila $b$ em ambiente sombreado. Para as plantas de Syagrus coronata, a incidência de luz total proporcionou maior razão clorofila $a / b$.

Paulilo (2000), em estudos com Euterpe edulis Mart., verificou aumento no teor de clorofila total e clorofila $b$ em plantas sob baixos níveis de radiação. Esses resultados corroboram o encontrado para Syagrus coronata por Carvalho et al. (2006). Dias (2015) infere que os diferentes níveis de luminosidade durante o crescimento inicial da Acrocomia aculeata não influenciaram na concentração de clorofila e carotenoides, evidenciando que a macaúba possui mecanismo eficiente de captação de luz, embora esse recurso possa ser um fator limitante para outras plantas.

Quanto às quantidades de carotenoides, neste trabalho não foi observada diferença entre as plantas de diferentes ambientes e estas apresentaram valores relativamente constantes ao longo do tempo (Figura 4A).

Os carotenoides são moléculas que também auxiliam no processo de absorção de luz e apresentam correlação positiva com as clorofilas, demonstrando que o incremento de umas influencia positivamente o aumento da outra. Os carotenoides são pigmentos acessórios que além de estarem associados às moléculas de clorofila e contribuir para promoção da coloração dos tecidos vegetais, desempenham papel essencial na fotoproteção, evitando danos ocasionados pelo excesso de radiação solar, que promovem excitação das moléculas de clorofila (TAIZ et al., 2017).

Os teores de clorofilas e carotenoides nas folhas são utilizados para estimar o potencial fotossintético das plantas, e, consequentemente, sua aclimatação e o crescimento em diferentes ambientes (REGO; POSSAMAI, 2006). Dessa forma, a capacidade da planta ajustar seu metabolismo para otimizar a utilização de recursos primários como a luz, determinará o sucesso ou o fracasso de sua aclimatação e estabelecimento sob diferentes ambientes (SILVA, 2014). 
Lemes e Loyola (2015) observaram que os modelos ecológicos de nicho são uma importante ferramenta no planejamento da conservação, por exemplo diante de mudanças climáticas, pois avaliam a distribuição potencial das espécies no presente e no futuro.

Figura 4 - Quantidade de clorofila $a$, clorofila $b$ e carotenoides (A) e relação clorofila $a / b$ (B) de plantas secas de Syagrus romanzoffiana, realocadas em três condições de luminosidade (clareira grande, clareira pequena e sombreamento) e avaliadas aos 4, 8 e 12 meses, em São Paulo - SP, Brasil. Médias seguidas pela mesma letra não diferem entre si, em nível de 5\% pelo teste Tukey. Letras comparam as condições dentro de uma determinada data

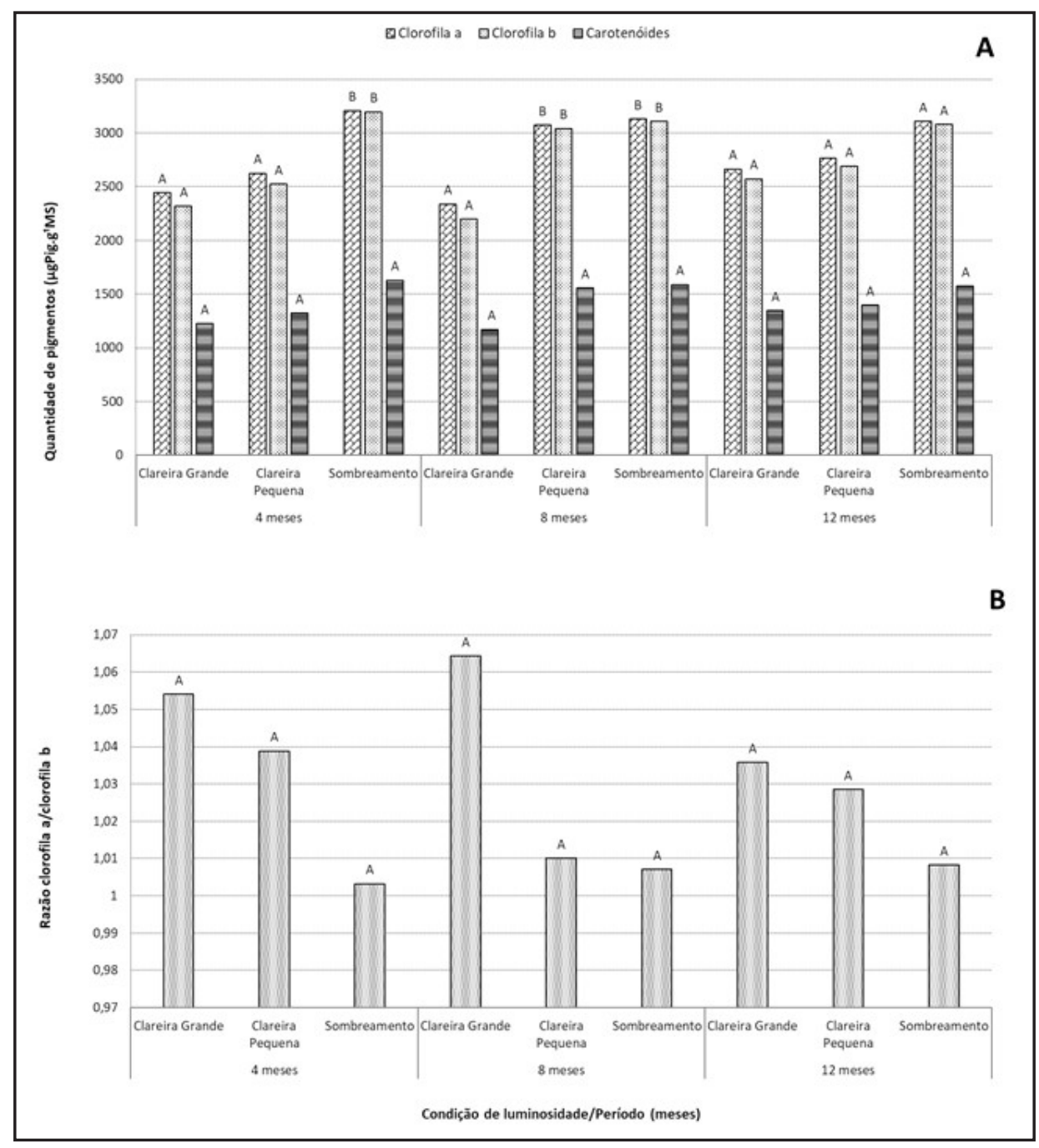

Fonte: Autores (2020) 
No geral, as taxas de sobrevivência de S. romanzoffiana foram altas, variando de 80 a 100\%, com valores superiores no ambiente sombreado e na classe de tamanho de torrão maior, a partir dos 8 meses. Os maiores valores de incremento em altura e diâmetro do coleto foram obtidos na clareira pequena e na classe de torrão maior, também a partir dos 8 meses da realocação. Para número de folhas, os maiores valores foram obtidos no ambiente clareira pequena e classe de torrão menor. Inicialmente, as maiores quantidades de clorofila $a$ e $b$ foram obtidas no ambiente sombreado, entretanto as quantidades se igualaram nos diferentes ambientes, ao final do período de um ano. Quanto à razão clorofila $a / b$, os resultados evidenciaram que, inicialmente, a razão foi maior nas plantas mantidas no sombreamento, com valores crescentes, também nos demais ambientes, igualando-se aos 12 meses.

\section{CONCLUSÃO}

Pode-se concluir que Syagrus romanzoffiana apresenta pouca restrição quanto ao ambiente de realocação, porém, com preferência às condições de clareira pequena, sendo dispensável que as mudas sejam realocadas com torrão de porte grande. Esses resultados podem contribuir para programas de restauração ambiental ou para enriquecimento de áreas naturais com espécimes resgatados de áreas com perturbação antrópica.

\section{AGRADECIMENTOS}

Órgãos financiadores: DERSA e Instituto de Botânica.

\section{REFERÊNCIAS}

ALVES, I. et al. Distribuição e padrão espacial da palmeira Syagrus pseudococos (Raddi) Glassman (Arecaceae), em um trecho de encosta na Serra do Mar, Ubatuba-SP, Brasil. Revista de Biociêcias da Universidade de Taubaté, Taubaté, v. 17, n. 2, p. 52-59, dez. 2011.

BERNACCI, L. C.; MARTINS, F. R.; SANTOS, F. A. M. dos. Estrutura de estádios ontogenéticos em população nativa da palmeira Syagrus romanzoffiana (Cham.) Glassman (Arecaceae). Acta Botanica Brasilica, São Paulo, v. 22, n. 1, p. 119-130, jan./mar. 2008. 
BRAHM, R. U. Efeito de substratos e do sombreamento no desenvolvimento de plantas de palmeira-juçara Euterpe edulis (Mart.) e palmeira-real Roystonea regia (Kunth). 2010. Dissertação (Mestrado em Sistemas de Produção Agrícola Familiar) - Universidade Federal de Pelotas, Pelotas, 2010.

BRANCALION, P. H. S.; NOVEMBRE, A. D. L. C.; RODRIGUES, R. R. Seed development, yield and quality of two palm species growing in different tropical forest types in SE Brazil: implications for ecological restoration. Seed Science and Technology, Bassersdorf, v. 39, n. 2, p. 412-424, jul. 2011.

CALEGARI, L. et al. Produção de mudas de espécies arbóreas nativas em viveiro via resgate de plantas jovens. Revista Árvore, Viçosa, MG, v. 35, n. 1, p. 41-50, jan./fev. 2011.

CAMEJO, D.; TORRES, W. High temperature effect on tomato (Lycopersicon esculentum) pigment and protein content and cellular viability. Cultivos Tropicales, Cuba, v. 22, n. 3, p. 13-17, 2001.

CARVALHO, N. O. S. et al. Crescimento inicial de plantas de licuri (Syagrus coronata (Mart.) Becc.) em diferentes níveis de luminosidade. Revista Árvore, Viçosa, MG, v. 30, n. 3, p. 351357, maio/jun. 2006.

DIAS, A. N. Capacidade de aclimatação à luz no estabelecimento inicial de macaúba (Acrocomia aculeata (Jacq.) Lodd. ex Mart.) em condições de viveiro e em campo. 2015. Dissertação (Mestrado em Manejo e Conservação de Ecossistemas Naturais e Agrários) - Universidade Federal de Viçosa, Viçosa, MG. 2015.

FERREIRA, D. F. Sisvar: a computer statistical analysis system. Ciência e Agrotecnologia, Lavras, v. 35, n. 6, p. 1039-1042, nov./dez. 2011.

FERREIRA, V. N. Distribuição espacial de indivíduos de Syagrus romanzoffiana (Cham.) Glassman em fragmento florestal da Mata Atlântica, São Luiz do Paraitinga-SP. 2007. Dissertação (Mestrado em Ciências Ambientais) - Universidade de Taubaté, Taubaté. 2007.

GIVINISH, T. J. Adaptation to sun and shade: a whole-plant perspective. Australian Journal of Plant Phisiology, Melbourne, v. 15, n. 2, p. 63-92, 1988.

INÁCIO, C. D.; LEITE, S. L. C. Avaliação de transplante de árvores em Porto Alegre, Rio Grande do Sul. Iheringia Série Botânica, Porto Alegre, v. 62, n. 1/2, p. 19-30, jan./dez. 2007.

JASPER, A. et al. Metodologia de salvamento de Bromeliaceae, Cactaceae e Orchidaceae na Pequena Central Hidrelétrica (PCH) Salto Forqueta - São José do Herval/ Putinga - RS - Brasil. Pesquisas, Botânica, São Leopoldo, v. 56, p. 265-284, 2005.

KNAPIK, P.; MARANHO, L. T. Avaliação da Revegetação em Área de Mineração, Região de Inundação do Rio Iguaçu, Araucária, PR. Revista Brasileira de Biociências, Porto Alegre, v. 5, n. 1, p. 507-509, 2007.

KÖPPEN, W. Climatologia: con un estudio de los climas de la tierra. Mexico: Fondo de Cultura Econômica, 1948. 479 p. 
LEMES, P.; LOYOLA, R. Mudanças climáticas e prioridades para a conservação da biodiversidade. Revista de Biologia Neotropical, Goiânia, v. 11, n. 1, p. 47-57, mar. 2015.

LEONHARDT, C. et al. Morfologia e desenvolvimento de plântulas de 29 espécies arbóreas nativas da área da Bacia Hidrográfica do Guaíba, Rio Grande do Sul, Brasil. Iheringia, Porto Alegre, v. 63, n. 1, p. 5-14, jan./jun. 2008.

LICHTENTHALER, $\mathrm{H}$. et al. Photosynthetic activity, chloroplast ultrastructure, and leaf characteristics of high-light and low-light plants and of sun and shade leaves. Photosynthesis research, The Hague, v. 2, n. 2, p. 115-141, jun. 1981.

LORENZI, H. (coord.). Palmeiras no Brasil: nativas e exóticas. Nova Odessa: Instituto Plantarum, 1996. 318 p.

MARTINS, J. R. et al. Teores de pigmentos fotossintéticos e estrutura de cloroplastos de Alfavaca-cravo cultivadas sob malhas coloridas. Ciência Rural, Santa Maria, v. 40, n. 1, p.6469, jan./fev. 2010.

MORAES NETO, S. P. et al. Crescimento de mudas de algumas espécies arbóreas que ocorrem na Mata Atlântica, em função do nível de luminosidade. Revista Árvore, Viçosa, MG, v. 24, n. 1, p. 35-45, jan. 2000.

NAVE, A. G. Banco de sementes autóctone e alóctone, resgate de plantas e plantio de vegetação nativa na Fazenda Intermontes, município de Ribeirão Grande, SP. 2005. Tese (Doutorado em Recursos Florestais) - Universidade de São Paulo, Piracicaba, 2005.

NODARI, R. O. et al. Crescimento de mudas de palmiteiro (Euterpe edulis Mart.) em diferentes condições de sombreamento e densidade. Revista Árvore, Viçosa, MG, v. 23, n. 3, p. 285-292, maio/jun. 1999.

OLIVEIRA, L. M. B. Sobrevivência e crescimento de mudas resgatadas em função do tempo de transplantio e níveis de sombreamento. 2014. Dissertação (Mestrado em Ciência Florestal) - Universidade Federal dos Vales do Jequitinhonha e Mucuri, Diamantina. 2014.

PAULILO, M. T. S. Ecofisiologia de plântulas e plantas jovens de Euterpe edulis Mart. (Arecaceae): Comportamento em relação à variação da radiação solar. Sellowia, Itajaí, v. 49-52, p. 93-105, 2000.

REGO, G. M.; POSSAMAI, E. Efeito do sombreamento sobre o teor de clorofila e crescimento inicial do jequitibá-rosa. Pesquisa Florestal Brasileira, Colombo, n. 53, p. 179-194, jul./dez. 2006.

RIBEIRO, M. C. et al. The Brazilian Atlantic Forest: how much is left, and how is the remaining forest distributed? Implications for conservation. Biological Conservation, Boston, v. 142, n. 6, p. 1141-1153, jun. 2009.

SANCHOTENE, M. do C. C. (coord.). Plano Diretor de Arborização de Vias Públicas. Porto Alegre: SMAM, 2000. 204 p. 
SANTOS JUNIOR, N. A.; TAMAKI, V. Realocação de plantas resgatadas em processos de supressão da vegetação: uma ação do Projeto Rodoanel Trecho Norte/SP. In: REUNIÃO ANUAL DO INSTITUTO DE BOTÂNICA, 21., 2014, São Paulo. Anais [...]. São Paulo: Instituto de Botânica, 2014. p. 1-4.

SÃO PAULO (Estado). Plano de Manejo do Parque Estadual da Cantareira. São Paulo: Fundação Florestal; Secretaria de Estado do Meio Ambiente, 2010. 586 p.

SILVA, D. V. Métodos não destrutivos para estimativas de clorofilas como indicadores da qualidade de mudas de espécies florestais. 2014. Dissertação (Mestrado em Produção Vegetal) - Universidade Estadual de Santa Cruz, Ilhéus. 2014.

SILVA, N. F. et al. Resgate de mudas de Lychnophora pohlii como alternativa para recuperação e conservação de campo rupestre. Floresta, Curitiba, v. 45, n. 3, p. 645-654, jul./set. 2015.

SOKAL, R. R.; ROHLF, F. J. Introducción a la Bioestadística. Barcelona: Editorial Reverté, 1980. $380 \mathrm{p}$.

TABARELLI, M. et al. A conversão da Floresta Atlântica em paisagens antrópicas: lições para a conservação da diversidade biológica das florestas tropicais. Interciência, Caracas, v. 37, n. 2, p. 88-92, fev. 2012.

TAIZ, L. et al. Fisiologia e desenvolvimento vegetal. 6. ed. Porto Alegre: Artmed, 2017. 858 p.

THIESEN, L. A. et al. Correlação de Pearson entre pigmentos fotossintetizantes e fitomassa de plantas de Aloysia triphylla. Journal of Environmental Analysis and Progress, Recife, v. 2, n. 3, p. 249-257, jul. 2017.

\section{Contribuição de Autoria}

\section{1 - Marina Crestana Guardia}

Bióloga, Dra., Pesquisadora Científica

https://orcid.org/0000-0002-8676-8648•mcguardia@ibot.sp.gov.br

Contribuição: Conceituação, Curadoria de dados, Análise formal, Investigação, Metodologia, Administração do projeto, Visualização, Escrita - primeira redação, Escrita - revisão e edição

\section{2 - Shoey Kanashiro}

Engenheiro Agrônomo, Dr., Pesquisador Científico

https://orcid.org/0000-0003-0118-1723•skanashi@uol.com.br

Contribuição: Conceituação, Análise formal, Investigação, Metodologia, Software, Escrita - primeira redação 


\section{3 - Vívian Tamaki}

Bióloga, Dra., Pesquisadora Científica

https://orcid.org/0000-0003-1426-9775•vtamaki@ibot.sp.gov.br

Contribuição: Análise formal, Investigação, Metodologia, Escrita - primeira redação, Escrita - revisão e edição

\section{4 - Catarina Carvalho Nievola}

Bióloga, Dra., Pesquisadora Científica

https://orcid.org/0000-0003-0627-1357•ccnievola@uol.com.br

Contribuição: Investigação, Escrita - revisão e edição

\section{5 - Rogério Mamoru Suzuki}

Biólogo, Dr., Pesquisador Científico

https://orcid.org/0000-0003-1124-9875•rsuzuki@ibot.sp.gov.br

Contribuição: Análise formal, Investigação, Metodologia, Escrita - primeira redação, Escrita - revisão e edição

\section{6 - Janaina Pinheiro Costa}

Bióloga, Ma., Assistente Técnica de Pesquisa Científica e Tecnológica https://orcid.org/0000-0001-5749-2753• janaina.pinheiro.ibt@gmail.com

Contribuição: Análise formal, Investigação, Recursos

\section{7 - Waldyr Baptista}

Técnico de Apoio à Pesquisa Científica e Tecnológica In memoriam

Contribuição: Investigação, Recursos

\section{8 - Yoshito Shidomi}

Auxiliar de Apoio à Pesquisa Científica e Tecnológica https://orcid.org/0000-0001-6098-4214 •yoshitoshidomi2020@gmail.com Contribuição: Investigação, Recursos

\section{9 - Mônica Valéria Cachenco}

Oficial de Apoio à Pesquisa Científica e Tecnológica https://orcid.org/0000-0003-4696-545X·mcachenco@ibot.sp.gov.br Contribuição: Investigação, Recursos 


\section{0 - Nelson Augusto dos Santos Junior}

Biólogo, Dr., Pesquisador Científico

https://orcid.org/0000-0002-9601-2350•njunior@ibot.sp.gov.br

Contribuição: Análise formal, Obtenção de financiamento, Investigação, Metodologia, Administração do projeto, Software, Visualização, Escrita - revisão e edição

\section{Como citar este artigo}

Guardia, M. C.; Kanashiro, S.; Tamaki, V.; Nievola, C. C.; Suzuki, R. M.; Costa, J. P.; Baptista, W.; Shidomi, Y.; Cachenco, M. V.; Santos Junior, N. A. Crescimento de Syagrus romanzoffiana (Cham.) Glassman após resgate e realocação em unidade de conservação urbana. Ciência Florestal, Santa Maria, v. 31, n. 1, p. 290-309, 2021. DOI 10.5902/1980509841654. Disponível em: https://doi.org/10.5902/1980509841654. Acesso em: xx mês abreviado 202x. 